\title{
Commentary: Understanding the relationship between acute kidney injury and durable ventricular assist device implantation: Is it a preoperative or postoperative event?
}

\author{
Francis D. Pagani, MD, PhD
}

\footnotetext{
From the Department of Cardiac Surgery, University of Michigan, Ann Arbor, Mich. Disclosures: Author has nothing to disclose with regard to commercial support.

Received for publication April 11, 2019; accepted for publication April 11, 2019; available ahead of print May 27, 2019.

Address for reprints: Francis D. Pagani, MD, PhD, Otto Gago, MD Endowed Professor of Cardiac Surgery, 5161 Cardiovascular Center, University of Michigan, 1500 E Medical Center Dr, Ann Arbor, MI 48109 (E-mail fpagani@umich.edu).

J Thorac Cardiovasc Surg 2020;159:489-90

$0022-5223 / \$ 36.00$

Copyright (C) 2019 by The American Association for Thoracic Surgery

https://doi.org/10.1016/j.jtcvs.2019.04.043
}

Durable left ventricular assist device (VAD) therapy affords significant survival, functional, and quality of life benefit. Although the benefits are substantial, the complexity of the operation in the setting of advanced heart failure is challenging and can result in significant end-organ dysfunction, complicating the perioperative course and long-term survival. Whereas numerous studies have examined the outcome of durable VAD implantation in the setting of renal dysfunction or dialysis, ${ }^{1-4}$ few have focused on the impact of durable VAD implantation on the incidence of new acute kidney injury.

In this issue of the Journal, Silver and colleagues ${ }^{5}$ investigated the outcomes of patients receiving durable LVAD therapy by examining the National Inpatient Sample (NIS) from 2008 to 2013, focusing on development of acute kidney injury (AKI) with or without dialysis. Silver and colleagues ${ }^{5}$ identified 8362 patients who underwent durable LVAD implantation, $3760(45.0 \%)$ of whom had AKI without the need for dialysis and $426(5.1 \%)$ of whom had AKI requiring treatment with dialysis. In-hospital mortalities were $3.9 \%$ for patients without AKI, $12.2 \%$ for those with AKI not requiring dialysis, and $47.4 \%$ for those with AKI requiring dialysis. Patients with AKI not requiring dialysis and those with $\mathrm{AKI}$ requiring dialysis had higher adjusted odds of mortality, major bleeding, sepsis, and discharge to a nursing facility. Of the patients who had AKI requiring dialysis, nearly 50\% died during the hospitalization, with only $30 \%$ discharged home.

These data are important and demonstrate (1) that the incidence of AKI associated with the hospitalization for durable VAD implantation is high; (2) that even AKI not requiring dialysis has significant adverse impact on VAD outcomes; and (3) that, as expected, AKI requiring dialysis has a high mortality. Not all previous studies, however, have demonstrated similar findings. ${ }^{6}$ The study by Brisco and colleagues ${ }^{6}$ from the Interagency Registry of Mechanically Assisted Circulatory Support (INTERMACS) importantly

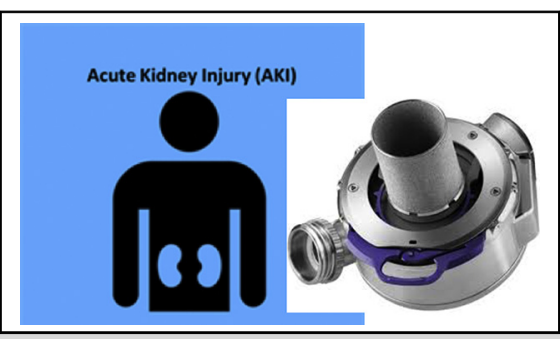

Durable ventricular assist device implantation and acute kidney injury.

\section{Central Message}

Hospitalizations associated with durable ventricular assist device implantation incur a high incidence of acute kidney injury that adversely effects prognosis.

See Article page 477. demonstrated that $61.3 \%$ of patients undergoing durable mechanical circulatory support implantation had an improvement in their estimated glomerular filtration rate of at least $20 \%, 39.3 \%$ had an improvement of at least $50 \%$, and $16.7 \%$ had an improvement of at least $100 \%$ within 1 month of implantation. Significant early deterioration in renal function was less common during this period, with a worsening of estimated glomerular filtration rate of at least $25 \%$ in $10.0 \%$ of patients and worsening of at least $50 \%$ in only $3.1 \%$. What might account for the discrepancies in findings? The study by Brisco and colleagues ${ }^{6}$ calculated estimated glomerular filtration rate from available laboratory data at baseline and at 1 week and 1, 3, 6, and 12 months after durable mechanical circulatory support implantation, whereas the study by Silver and colleagues ${ }^{5}$ relied on administrative coding available in the NIS. The NIS also lacks details on the nature and sequence of events during a hospitalization. As a result, the study by Silver and colleagues ${ }^{5}$ could not necessarily determine the timing of an AKI episode (ie, days after hospital admission), its cause, or whether AKI not requiring dialysis occurred before or after implantation of a durable VAD. In addition, the NIS does not contain individual patient identifiers, so multiple hospitalizations of the same patient may be represented.

Despite the limitations of the study of Silver and colleagues, ${ }^{5}$ these findings highlight a concern for a high 
incidence of AKI associated with durable VAD therapy. Future efforts should be directed at identifying preventive strategies, including closer to optimal timing of durable VAD implantation, less-invasive approaches that could eliminate the need for cardiopulmonary bypass, and improved postoperative management.

\section{References}

1. Cowger J, Sundareswaran K, Rogers JG, Park SJ, Pagani FD, Bhat G, et al. Predicting survival in patients receiving continuous flow left ventricular assist devices: the HeartMate II risk score. J Am Coll Cardiol. 2013;61: 313-21.
2. Kirklin JK, Naftel DC, Kormos RL, Pagani FD, Myers SL, Stevenson LW, et al. Quantifying the effect of cardiorenal syndrome on mortality after left ventricular assist device implant. J Heart Lung Transplant. 2013;32:1205-13.

3. Kilic A, Chen CW, Gaffey AC, Wald JW, Acker MA, Atluri P. Preoperative renal dysfunction does not affect outcomes of left ventricular assist device implantation. J Thorac Cardiovasc Surg. 2018;156:1093-101.e1.

4. Bansal N, Hailpern SM, Katz R, Hall YN, Kurella Tamura M, Kreuter W, et al. Outcomes associated with left ventricular assist devices among recipients with and without end-stage renal disease. JAMA Intern Med. 2018;178:204-9.

5. Silver SA, Long J, Zheng Y, Goldstone AB, Franz D, Chang TI, et al. Outcomes after left ventricular assist device implantation in patients with acute kidney injury. J Thorac Cardiovasc Surg. 2020;159:477-86.e3.

6. Brisco MA, Kimmel SE, Coca SG, Putt ME, Jessup M, Tang WW, et al. Prevalence and prognostic importance of changes in renal function after mechanical circulatory support. Circ Heart Fail. 2014;7:68-75. 